\title{
Biliary papillomatosis in the common bile duct
}

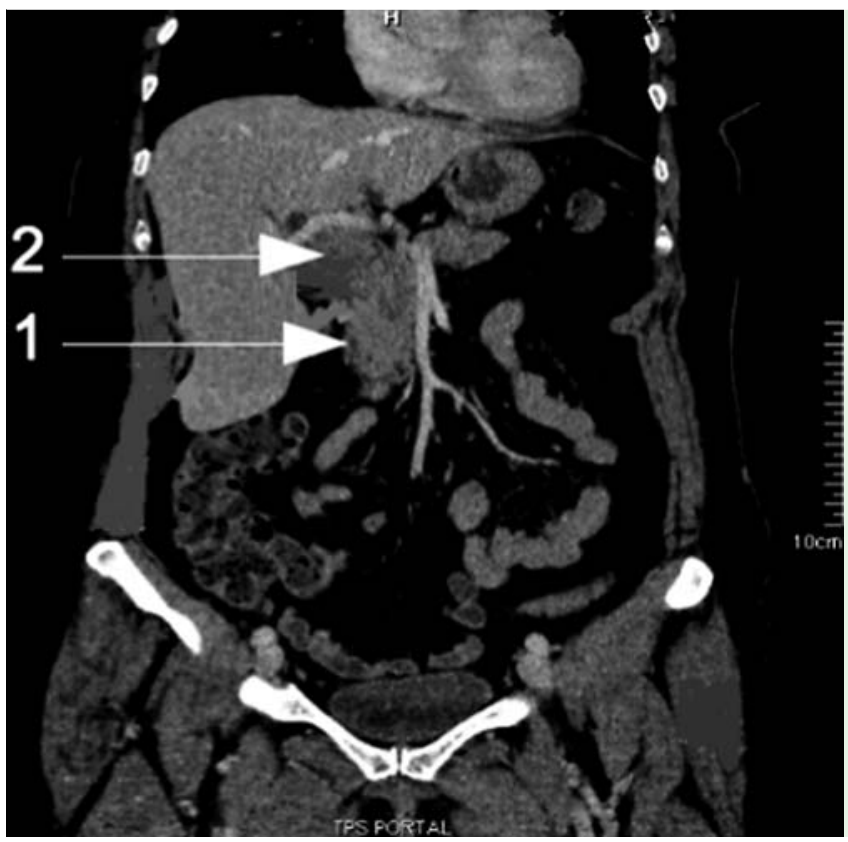

Fig. 1 Computed tomography (CT) scan of a 62-year-old woman with abdominal pain and an irregular hyperechoic pseudomass of the gallbladder on ultrasound showing an abnormal tissue mass at the hilum of the liver ( 1 , common bile duct; 2, tumor mass).

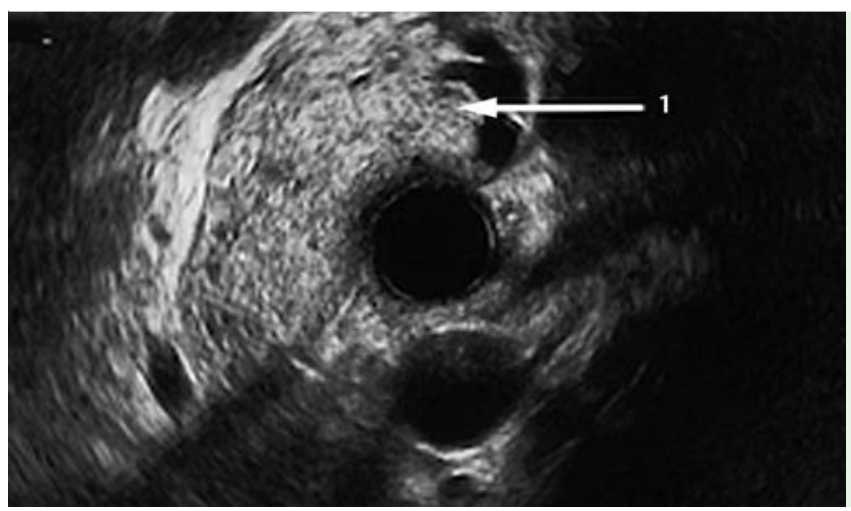

Fig. 3 Biliopancreatic endoscopic ultrasound (EUS) showing an abnormal piece of tissue floating at the upper pole of the common bile duct (1, tumor mass).

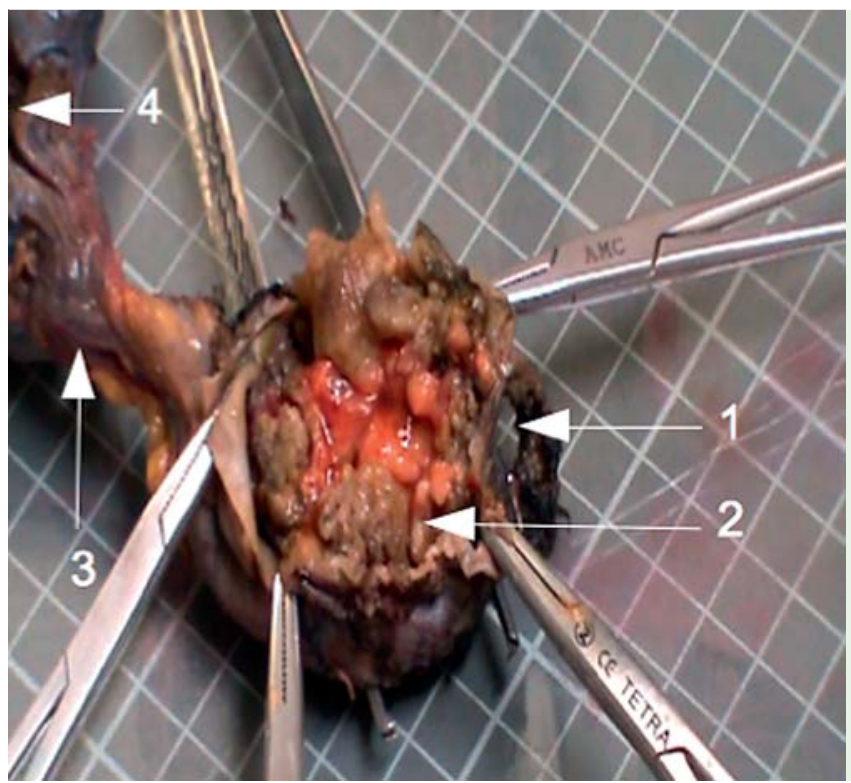

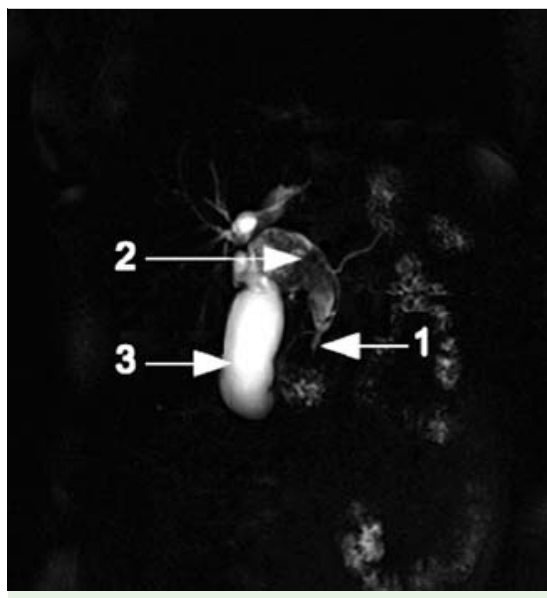

Fig. 2 Biliary magnetic resonance imaging (MRI) scan confirming the presence of the abnormal tissue mass at the hilum of the liver ( 1 , common bile duct; 2 , tumor mass; 3 , gall bladder).

A 62-year-old woman was admitted to our hospital with abdominal pain. Clinical examination revealed definite tenderness in the right hypochondrium only. Laboratory assessment on admission was normal. An abdominal ultrasound was performed, which showed an irregular hyperechoic pseudomass of the gallbladder.

An abdominal contrast-enhanced computed tomography (CT) scan ( $\bullet$ Fig. 1 ) and a magnetic resonance imaging (MRI) scan of the liver $($ Fig. 2 ) revealed the presence of an abnormal tissue mass at the hilum of the liver. The suspected diagnosis was confirmed by biliopancreatic endoscopic ultrasound (EUS), which showed an abnormal piece of tissue floating at the upper pole of the common bile duct ( Fig.3). The tissue was not invading the common bile duct wall and the endoluminal choledochal surface was intact. These results suggested a benign endoluminal lesion so no biopsy was performed.

The case was discussed by the multidisciplinary oncological team who decided that surgery should be performed. The resected tissue included the gallbladder, extrahepatic bile ducts, and hilar and retropancreatic lymph nodes ( $\bullet$ Fig.4). A hepaticojejunal anastomosis (RouX-en-Y) was created. The postoperative period was uncomplicated. At microscopic examination, the intraductal region of papillomatosis was found to be surrounded by an invasive tumor, a typical well-differen- 
tiated cholangiocarcinoma that was classified as pT1N0M0.

Biliary papillomatosis is an extremely rare disorder [1]. We here report a case of biliary papillomatosis that manifested as vague abdominal pain only. Our treatment option was based on the potential for malignant transformation.

Most patients with this condition present with clinical symptoms of jaundice and acute cholangitis [2-4]. Nevertheless, biliary papillomatosis can also remain latent many years [5]. Medical imaging can sometimes help in the diagnosis with retrograde cholangiography showing multiple filling defects and a dilated biliary tree with serrated irregularity of the bile duct wall $[2,3]$. The diagnosis can be confirmed by intraductal biopsies or by studying the cytology of any secretions. The best treatment is radical liver and biliary surgery with an $\mathrm{R} 0$ resection.

Although rare, biliary papillomatosis must be kept in mind when examining a patient suffering from obstructive jaundice who does not have gallstones. Before the final choice of treatment is made, the possibility of a malignant transformation must be assessed with endoscopic retrograde cholangiography, brush biopsy, and core biopsy.

\section{Endoscopy_UCTN_Code_CCL_1AZ_2AN}

Competing interests: None

\section{R. Kassir ${ }^{1}$, G. Barabino ${ }^{1}$, S. Bageacu ${ }^{1}$, G. Ferrari ${ }^{1}$, K. Abboud1', O. Dumas², M. Peoc'h ${ }^{3}$, J. Porcheron ${ }^{1}$}

${ }^{1}$ Department of Digestive Surgery, CHU Hospital, Jean Monnet University, Saint Etienne, France

2 Department of Hepatogastroenterology, CHU Hospital, Jean Monnet University,

Saint Etienne, France

${ }^{3}$ Department of Pathology, CHU Hospital, Jean Monnet University, Saint Etienne, France

\section{References}

1 Vassiliou I, Kairi-Vassilatou E, Marinis A et al. Malignant potential of intrahepatic biliary papillomatosis - a case report and review of literature. World J Surg Oncol 2006; 4: 71

2 Yeung YP, Ah Chong K, Chung CK et al. Biliary papillomatosis: report of seven cases and review of English literature. J Hepatobiliary Pancreat Surg 2003; 10: 390 - 395

3 Lee SS, Kim MH, Lee SK et al. Clinicopathologic review of 58 patients with biliary papillomatosis. Cancer 2004; 100: 783-793

$4 \mathrm{Ma} K F$, Iu PP, Chau LF et al. Clinical and radiological features of biliary papillomatosis. Australas Radiol 2000; 44: 169-173

5 Neumann RD, Livolsi VA, Rosenthal NS et al. Adenocarcinoma in biliary papillomatosis. Gastroenterology 1976; 70: 779-782

\section{Bibliography}

Dol http://dx.doi.org/

10.1055/s-0033-1344163

Endoscopy 2013; 45: E197-E198

(c) Georg Thieme Verlag KG

Stuttgart · New York

ISSN 0013-726X

Corresponding author

\section{R. Kassir, MD}

Department of Digestive Surgery CHU Hospital, Jean Monnet University Avenue Albert Raimond 42270 Saint-Priest-en-Jarez France

Fax: +33-477-127015

Radwankassir42@hotmail.fr 